\begin{tabular}{ll}
\hline \hline MINING AND METALLURGY INSTITUTE BOR & ISSN: 2334-8836 (Štampano izdanje) \\
UDK: 622 & ISSN: 2406-1395 (Online) \\
\hline \hline
\end{tabular}

\title{
APPLICABILITY OF THE SHORTWALL MINING METHODS IN REMBAS MINE PITS ${ }^{* * *}$
}

\begin{abstract}
In the Rembas mine pits, the coal exploitation lasts for more than one century. During this period, most of coal reserves have been mined, so there is a need for introduction the new and modern technical solutions, which will enable rationalization of exploitation, higher productivity, safety on operations and better operation conditions with lower investments. In the Rembas mine pits for coal exploitation, the low-productive pillar mining methods are used. During the eighties of the last century in some pits, the mechanized longwall mining method was applied, but the expensive equipment and complex naturalgeological conditions in the area Resava-Moravian coal basin restrict application of this metod. Bad financial situation, as well as the increasingly difficult operation conditions of exploitation, indicate a need to apply some of the methods which would be technically justified, and whose cost of exploitation would be proportional to the possibilities of mine. In this paper, the possibilities for application the shortwall mining methods are considered with their advantages compared to the previously applied mining methods in the Rembas mine.
\end{abstract}

Keywords: underground mining, mining methods, shortwall mining, Rembas mine.

\section{INTRODUCTION}

Rembas is the undergound coal mine with the head office in Resavica. It is a part of the Public Enterprise for Underground Coal Exploitation Resavica. The Rembas mine has a long tradition, over 150 years of coal exploitation and very rich history [1]. Currently, within the Rembas mine, there are four active pits: "Jelovac", "Strmosten", "Ravna Reka - IV block" and "Senjski Rudnik".

During a long-term coal mining from the area Resava-Morava coal basin, most of the coal reserves have been exploited. As the dominant systems of mining in deposits of this basin, the classical pillar mining methods were applied in different forms. The choice of these mining methods is caused by the deposit conditions which are not particularly favorable. Exploitation conditions in the Rembas mine pits are characterized by the expressed tectonics, relatively unfavorable physical-mechanical properties of the operation environment, variable thicknesses of coal seams, coal tendency for spontaneous self-ignition and presence of dangerous coal dust and hazardous gases in some pits [2].

According to the Book of coal reserves, the state of balance reserves on December 31, 2016 amounted to [3]:

\footnotetext{
* Technical Faculty Bor, University of Belgrade, V.J. 12, 19210 Bor, Serbia, e-mail:vmilic@tfbor.bg.ac.rs, mlradovanovic@tfbor.bg.ac.rs

** The work is the result of the Project TR 33038 "Improvement the Technology of Copper Ore Mining and Processing with Monitoring of Living and Working Environment in RTB Bor Group ", funded by the Ministry of Education, Science and Technological Development of the Republic of Serbia
} 
Table 1 State of balance coal reserves in "Rembas" mine (in tonnes)

\begin{tabular}{|c|c|c|c|c|}
\hline \multirow{2}{*}{ Deposit } & \multicolumn{4}{|c|}{ Category } \\
\cline { 2 - 5 } & $\mathbf{A}$ & $\mathbf{B}$ & $\mathbf{C}_{\boldsymbol{1}}$ & $\mathbf{A}+\mathbf{B}_{\mathbf{1}} \mathbf{C}_{\boldsymbol{1}}$ \\
\hline Ravna Reka & 419790 & 849380 & 880770 & 2149940 \\
\hline Senjski Rudnik & 117070 & 131130 & 192480 & 440680 \\
\hline Strmosten & 371230 & 984990 & 1690930 & 3047150 \\
\hline Jelovac & 610 & 1085440 & 514600 & 1600650 \\
\hline
\end{tabular}

Considering the coal exploitation is taking place at ever greater depths and in increasingly difficult conditions, there is a need for application of more efficient mining methods which, in addition to the lower investments and minimal costs, will enable more rational exploitation of the remaining coal reserves. Since the opening of underground coal mines, mostly low-production pillar mining methods have been used, so there is a need for implementation a new more mechanistic method that will enable the production increase, with far better indicators, better working conditions and significantly better level of safety in operations. Due to the complex geological conditions in the deposits, as well as due to the necessary high investments for application the longwall mining methods, the most realistic solution is the application of shortwall mining method by a direction of dip, with drilling and blasting technology and obtaining the roof coal.

In the "Senjski Rudnik" pit exploitation is carried out under the old works; the remaining coal reserves are low and mining will come to the end for couple of years. Due to this, it does not need to count on the new technological solutions of mining.

For the other pits in Rembas mine possibility for application the shortwall mining method will be represented on an example of the "Ravna Reka-IV block" pit.

\subsection{Geological Structure of the Ravna Reka Deposit}

In the deposit "Ravna Reka-IV block" in the coal-bearing horizon, there is a seam of good quality brown coal. Coal seam has a complex structure, and it is divided in two branches. The thickness of the coal seam ranges from $2.2 \mathrm{~m}$ to $18.1 \mathrm{~m}$, the thickness of pure coal is from $0.5 \mathrm{~m}$ to $12 \mathrm{~m}$, while the average thickness of pure coal is $4.54 \mathrm{~m}$. The direction of the coal seam is, generally, east - west, with a fall of $12^{\circ}-15^{\circ}$ towards the north. The coal seam floor is made of gray-white to greenish clay sands, alumina and coal clays. Crossing between the floor series and coal seam was built mainly from coal clays. The coal seam roof is presented in the normal primary conditions with grayish-whitish marl, while in the intermediate and western parts of the deposits it is eroded by the pulled-over red Permian sandstone. Intermediate waste in the coal seam is represented by coal clay from $0.2 \mathrm{~m}$ to $4.7 \mathrm{~m}$ thickness and clayed sandstone from $0.3 \mathrm{~m}$ to $2.1 \mathrm{~m}$ thickness. These interlayers are completely absent in some parts of the deposit, and coal seam appears as a single compact seam without intermediate rock [4].

\section{DESCRIPTION OF THE SHORTWALL MINING METHOD}

The application of shortwall mining methods should represent a transition the classic pillar and longwall mining methods. 
In shortwall mining methods, the face lengths are relatively small, not more than 20-30 m, which allows better adjustment to the specific conditions in deposit [5]. Depending on the conditions in deposit, there is a possibility to increase the face length, but also reduce it if there is a justification for this. The application of some of the possible shortwall mining method variants should enable the increase face length in order. Elimination of separate ventilation and elimination or reducing the use of timber support improves the operation conditions and safety on the excavation process [5].

\subsection{Principle of Excavation}

Currently, the exploitation on the Ravna Reka deposit is carried out in the "Ravna Reka-IV block" pit in the mining field OP-1 using the pillar " $\mathrm{G}$ " method. In the mining fields OP-2 and OP-3, the conditions in the deposit are such that they enable the application of shortwall mining method by the full dip direction of coal seam. Within the development phase, the mining field OP-2 is divided into pillars per a coal seam strike by drivage a haulage and ventilation drift at a distance of $40 \mathrm{~m}$. For the next pillar per strike, a new ventilation drift is driven instead of preserving the haulage drift of the previous pillar. On that way, between two strike pillars at a distance of $8 \mathrm{~m}$, a protective pillar is created, through which the ventilation connections are made. At the end of the mining field, a preparatory incline between haulage and ventilation drift is driven. In this incline, the shortwall excavation equipment is installed: double chain excavation conveyor and friction or hydraulic props with steel or timber roof beam. Obtaining of coal in face is carried out by the drilling-blasting works, while the friction support is used for supporting the shortwall face. Double chain conveyor is used for removal the cast coal. This kind of a shortwall face structure enables a flow-through ventilation, while a separate ventilation is used during the shortwall preparation phase. Figure 1 shows the construction of a shortwall face.

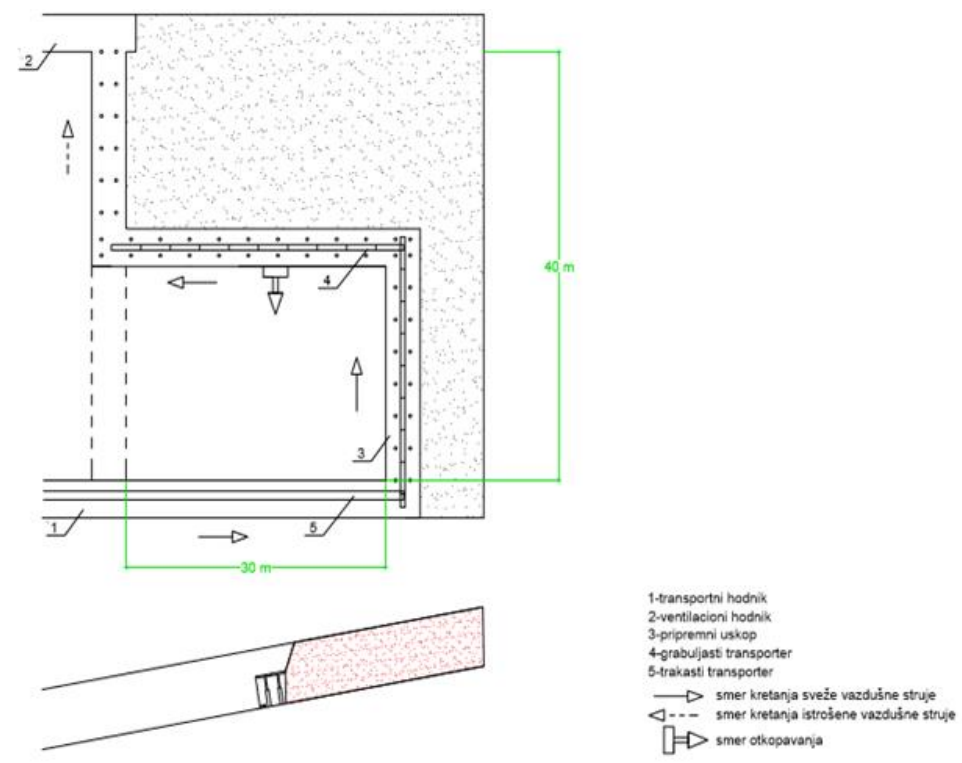

Figure 1 Construction of a shortwall face by a distance of full dip 
The shortwall work technology consists of two basic phases, which are repeated cyclically. In the first phase, the coal undercutting is carried out in the subsection part of a shortwall face by the drilling-blasting works. Therefore setting support, loading and removal of coal are carried out. In the second phase, after the certain face progress in the subsection part and after removal the friction props from a demolition line, coal is obtained from the upper part of coal seam. Obtaining of a roof coal can be done alternately at the face; while in one part of the face there is excavation in a subsection, in the second part the caving of the roof coal will be done. The work cycle is shown in Figure 2.

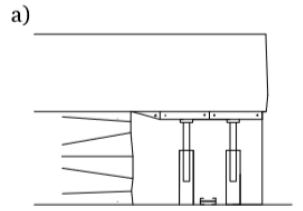

b)

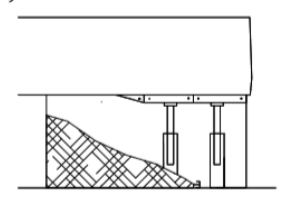

c)

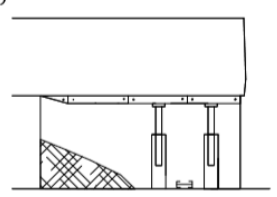

The selected friction support, its carrying capacity, the layout and face advance (which causes a short open stope time) should ensure that the all projected phases are normalized without the difficulties caused by the face deformation of face due to the impact of the rock pressure in the excavation area.

For excavation in the first phase, the excavation height can be maintained as with the existing pillar " $G$ " method applied in the "Ravna Reka-IV blok" pit, due to the existing drilling equipment. The height of the upper part of the coal, which is obtained in the second phase, is conditioned by the coal steam thickness.

d)

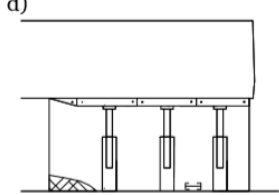

e)
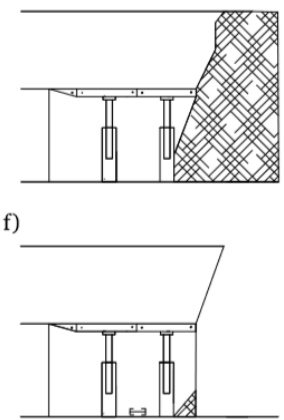

Figure 2 The cycle of work at a shortwall face: a) drilling in the subsection, b) coal loading after blasting, $c$ ) setting of the roof beam, d) setting of the friction prop, e) obtaining the roof coal, f) moving conveyor to the starting position

\subsection{Parameters of Drilling and Blasting}

The specific consumption of explosives depends mainly on the characteristics of the rock mass, selected type of explosive and surface of the room cross-section.

The specific consumption of explosives could be defined by the following relations [6]:

$$
\begin{aligned}
q & =0.4 \cdot\left(\sqrt{0.2 \cdot f}+\frac{1}{\sqrt{S}}\right)^{2} \cdot e \cdot k= \\
& =0.34\left[\mathrm{~kg} / \mathrm{m}^{3}\right]
\end{aligned}
$$

where:

$e=480 / A_{x}$ - coefficient of working ability of explosives, 
Ax $=190\left[\mathrm{~cm}^{3}\right]$ - working capacity of methane permitted explosive Metandetonit,

$k=1$ - coefficient which characterizes the necessary quality of the rock crushing,

$\mathrm{f}=0.8$ - strenght ratio, ting.

$\mathrm{S}$ - surface of the cross section for blas-

According to the Rulebook on Technical Norms for Handlings of Explosives and Blasting in Mining, only the methane millisecond detonators may be used, whereby in the adjacent drillholes it can be detonators of the same number or adjacent higher or lower number of deceleration interval. Also the sum of deceleration interval cannot exceed $136 \mathrm{~ms}$. Because of that, the blasting will be performed in sections of $10 \mathrm{~m}$, so the cross section area of one section will be $\mathrm{S}=30 \mathrm{~m}^{2}$.

The resulting value is increased by $5 \%$, and the specific consumption of explosives will be:

$$
\mathrm{q}=1.05 \cdot 0.34=0.357\left[\mathrm{~kg} / \mathrm{m}^{3}\right]
$$

The required number of drillholes could be calculated according to the formula [6]:

$$
N=\frac{1.27 \cdot q \cdot S}{d^{2} \cdot g \cdot k_{p}}=26.5
$$

where:

$\mathrm{q}=0.34\left[\mathrm{~kg} / \mathrm{m}^{3}\right]$ - specific consumption of explosives,

$\mathrm{S}=30\left[\mathrm{~m}^{2}\right]$ - surface of the cross section for blasting,

$\mathrm{d}_{\mathrm{p}}=32[\mathrm{~mm}]$ - diameter of cartridge,

$\mathrm{g}=1150$ - density of explosive Metandetonit, [7].

$\mathrm{k}_{\mathrm{p}}=0.435$ - drillhole loading coefficient

$$
\begin{aligned}
& \mathrm{k}_{\mathrm{p}}=\mathrm{k}_{\mathrm{p}}{ }^{\prime} \cdot \mathrm{k}_{\mathrm{p}}{ }^{\prime}=0.75 \cdot 0.58=0.435 \\
& \mathrm{kp}^{\prime}=\frac{{ }^{l} p}{l_{b}}=\frac{0.78}{1.03}=0.75
\end{aligned}
$$

where:

$1_{p}$ - loading length of drillhole, $l_{b}$ - the length of drillhole.

$$
\mathrm{kp}^{\prime \prime}=\frac{\frac{d_{p}^{2} \pi}{\frac{d_{b}^{2} \pi}{4}}}{{ }^{2}}=\frac{d_{p}^{2}}{d_{b}^{2}}=\frac{0.32^{2}}{0.42^{2}}=0.58
$$

where:

$\mathrm{d}_{\mathrm{p}}$ - diameter of cartridge,

$\mathrm{d}_{\mathrm{b}}$ - diameter of drillhole.

The length of borehole can be calculated according to the formula:

$$
\mathrm{k}_{\mathrm{ib}}=1_{\mathrm{sm}} / \mathrm{l}_{\mathrm{b}} \Rightarrow 1_{\mathrm{b}}=1_{\mathrm{sm}} / \mathrm{k}_{\mathrm{ib}}=1.03[\mathrm{~m}]
$$

where:

$1_{\mathrm{sm}}=1[\mathrm{~m}]$ - predicted advance per shift,

$\mathrm{k}_{\mathrm{ib}}=0.97$ - coefficient of drillhole utilization.

The required amount of explosives could be calculated according to the formula:

$\mathrm{Q}=\mathrm{q} \cdot \mathrm{S} \cdot \mathrm{l}_{\mathrm{b}} \cdot \mathrm{k}_{\mathrm{ib}}=10.7[\mathrm{~kg}]$

Quantity of explosives per one drillhole:

$\mathrm{Q}_{1}=\mathrm{Q} / \mathrm{N}=0.4153[\mathrm{~kg}]$,

it being adopted $0.42[\mathrm{~kg}]$

Quantity of explosives needed for the center cut:

$\mathrm{Q}_{\mathrm{z}}=\mathrm{Q}_{1} \cdot 1.2=0.504[\mathrm{~kg}]$

Quantity of explosives needed for the auxiliary drillholes:

$\mathrm{Q}_{\mathrm{p}}=\mathrm{Q}_{1} \cdot 1.1=0.462[\mathrm{~kg}]$

The following quantity of explosives is adopted:

$$
\mathrm{Q}_{\mathrm{z}}=0.5[\mathrm{~kg}]
$$$$
\mathrm{Q}_{\mathrm{p}}=0.5[\mathrm{~kg}]
$$

The corrected number of drillholes will be:

$$
\mathrm{N}_{\mathrm{b}}=\mathrm{Q} / \mathrm{Q}_{1}=25.47
$$

The 26 drillholes, 4 in centre cut and 22 auxiliary drillholes are adopted.

The corrected quantity of explosives for one blast will be:

$$
\mathrm{Q}=22 \cdot 0.5+4 \cdot 0.5=13[\mathrm{~kg}]
$$


Considering the number of drillholes, drilling according to the schedule given in Figure 3 is adopted. Initiation of loadings is done by the millisecond electric detonators, intended for use in the methane mode. In this case, four slowdown intervals are used.
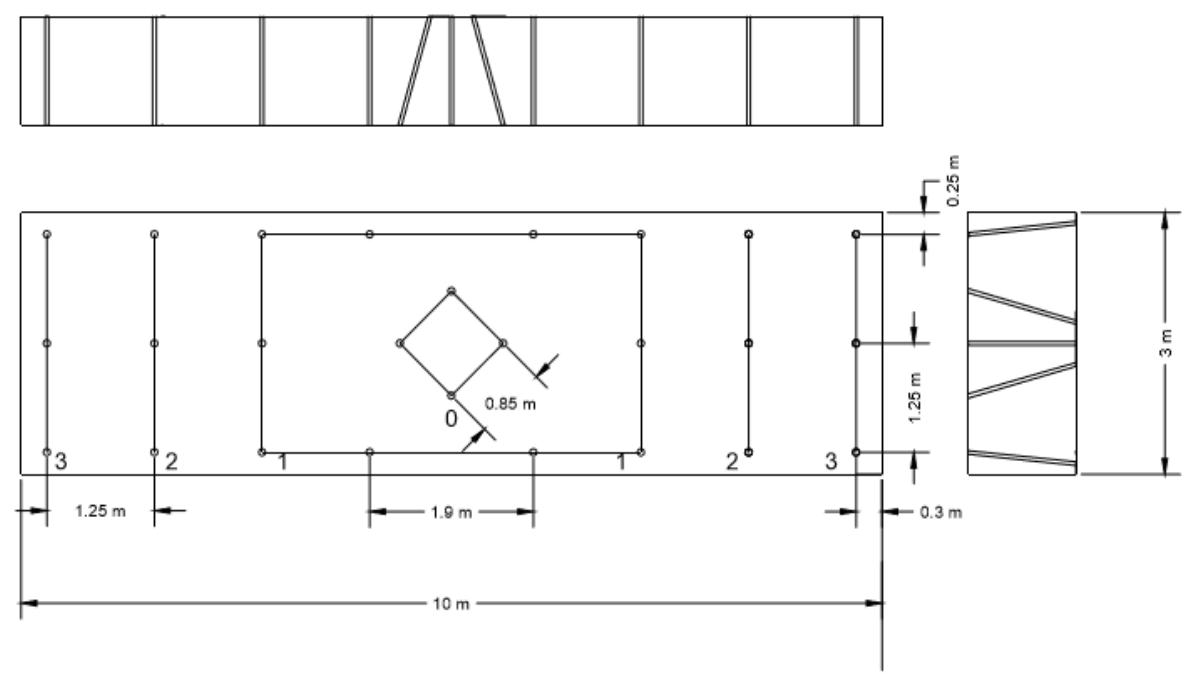

Figure 3 Drilling diagram and order of loading initiation at the coal face with the center cut (interval of slowing is $34 \mathrm{~ms}$ )

The roof coal is obtained in sections of $3 \mathrm{~m}$ long by the blasting of drillholes with a lenght equal to the roof coal thickness. For a specific consumption of explosive, a lower value is taken than for blasting in coal face, because a large slope and gravity have a positive influence on the coal collapse.

Using the shortwall mining method, i.e. increasing the face length, an increase in productivity could be achieved, the number of excavation units could be decreases, organizational conditions could be impro-ved, and utilization of the haulage system could be increased. It would also reduce the costs of timber consumption, reduce the hard physical labor, as well as the number of preparatory units. The flow-through ventilation ensures safety and better climate conditions, especially in methane pits.

\section{RESULTS AND DISCUSSION}

By comparison the face parameters and mining method indicators, it can be concluded that the application of the shortwall mining method has many advantages over the pillar mining methods, such as:

- a significantly lower preparation ratio than in the pillar methods,

- better excavation effects,

- higher excavation intensity,

- drilling of roof coal is carried out from the supported area, which also improves the operation conditions and safety on coal face,

- by increasing the shortwall face lenght, an increase of shortwall face output and excavation productivity is ensured, 
- number of preparatory units and number of workers on preparation are reduced, as well as the cost of supporting,

- better organization with significantly better operation conditions, and

- higher recovery, less losses and less dilution.
Table 2 present the calculated indicators in case of application the shortwall mining method for miningthe field OP-2 in comparison with the same indicators for mining the field OP-2 in case of the pillar G method application.

Table 2 Comparative overview of indicators of the applicable mining methods for the Ravna Reka deposit

\begin{tabular}{|l|c|c|c|c|}
\hline Mining method & $\begin{array}{c}\text { Preparation } \\
\text { ratio [m/t] }\end{array}$ & $\begin{array}{c}\text { Shortwall face } \\
\text { efficiency } \\
{[\mathbf{t} / \mathbf{s m}]}\end{array}$ & $\begin{array}{c}\text { Excavation } \\
\text { effects } \\
{[\mathbf{t} / \mathbf{n a d}]}\end{array}$ & $\begin{array}{c}\text { Excavation } \\
\text { intensity } \\
{\left[\mathbf{t} / \mathbf{m}^{\mathbf{2}}\right]}\end{array}$ \\
\hline Pillar G method & 0.0139 & 34.58 & 8.89 & 5.87 \\
\hline $\begin{array}{l}\text { Shortwall min- } \\
\text { ing method }\end{array}$ & 0.00503 & 48.53 & 12.1325 & 6.13 \\
\hline
\end{tabular}

On the basis of all the considered parameters, it can be said that the proposed shortwall excavation is more than an adequate replacement for the pillar methods, both from the aspect of better productivity and organization, and from the aspect of financial profit.

\section{CONCLUSION}

The low productive pillar mining methods are applied for the coal excavation in the "Ravna Reka-IV block" pit. Observing the conditions of coal exploitation in the "Ravna Reka-IV block" pit, as well as observing the technical possibilities, the structure of the existing workers and Rem-bas mine financial situation, an analysis of possibility for application the shortwall mining method by direction the full dip of coal seam was performed.

Relative to the mechanized longwall mining method, along significantly lower investments, the advantage of the shortwall mining method is reflected in much better adjustment to the specific conditions in the deposit due to the occurrence of tectonics and irregularity. In comparison with the applied pillar mining methods, this method achieves higher face output, better excavation effects, lower preparation ratio, higher excavation intensity, and significantly higher productivity.

The technical solution of the excavation given in this paper enables more reliable operation, better working conditions caused by the flow-through ventilation, reduced participation of manual labor, because most materials fall on the chain conveyor, while the works on the face supporting are facilitated due to the application of friction props.

Due to the all above, the application of shortwall mining method by direction the full dip of coal seam is imposed as a quality and serious solution for ensuring the continuity, stabilization and improvement of production in the "Ravna Reka-IV block" pit.

\section{REFERENCES}

[1] http:/www.jppeu.rs/rembas.html

[2] Ivkovic M. et all, Natural and Geological Conditions of Coal Mining in the Pits of the Brown Coal Mine "Rembas"- Resavica, Technics Technologies Education Management, Number 2, Volume 7, (2012), 673-678

[3] Tehnička dokumentacija JP PEU "Resavica", JP PEU Resavica, Resavica 2017. 
[4] Group of authors, Main Mining Design for Coal Exploiotation of the Deposit "Ravna Reka" Locality "IV block" RMU Rembas - Resavica, Ugalj projekt, Belgrade, 2010 (in Serbian)

[5] Milićević Ž., Methods of Underground Mining the Deposits of Mineral Resources, Technical Faculty in Bor, Bor, 2011, p.71 (in Serbian)
[6] Milićević Ž., Design the Mines with Underground Exploitation, Technical Faculty in Bor, Bor, 2007 (in Serbian)

[7] Milićević Ž., Technology of Underground Mining the Deposits of Mineral Resources, Technical Faculty in Bor, Bor, 2013, p. 221 (in Serbian) 